\title{
Delayed gratification is better than no gratification
}

\author{
Anthony W. Kim, MD
}

See related article on pages 745-50.

It will not come as a surprise to anyone reading this editorial that much of the joy of being a surgeon stems from the ability to achieve successful results in an almost immediate manner. The development of postoperative complications frequently prevents surgeons from realizing a sense of immediate gratification; fortunately, most complications are surmountable and simply allow for satisfaction to arrive in a delayed fashion. Some complications, however, truly challenge the notion that even delayed gratification is achievable. A postpneumonectomy pleural space infection is a dreaded and difficult problem to manage and possibly one such example of the aforementioned type of complication. Addressing this problem entails a significant investment of time and effort on the parts of both the surgeon and the patient. Although having a patient survive this complication is in itself a major victory, the inevitable recurring visits to address wound-related issues serve as a reminder that the current approaches to address this problem are far from a solution that allows for the realization of a sense of gratification in any immediate or intermediate time frame.

In their article in this issue of the Journal by Perentes and colleagues, ${ }^{1}$ they present a consecutive series of 21 patients during an 8-year period who had postpneumonectomy pleural space infections that were managed with wound vacuum therapy. Of remarkable note, wound closure was achieved in 19 of 21 patients $(90 \%)$, with a mean time to closure of 23 days. On the surface, 21 patients may seem to be a rather small number; however, if one were to estimate a postpneumonectomy pleural space infection incidence of $5 \%$, as reported by Perentes and colleagues in their response to the original reviewers' critiques and recently reported elsewhere, ${ }^{2}$ their cohort would be reflective of a denominator of 420 pneumonectomies. As a result, their experience represents a substantial series spanning a relatively short period. Perentes and colleagues' mean time to closure is also notable when compared to the times

\footnotetext{
From the Section of Thoracic Surgery, Yale School of Medicine, New Haven, Conn. Disclosures: Author has nothing to disclose with regard to commercial support.

Received for publication Nov 21, 2014; accepted for publication Nov 24, 2014; available ahead of print Jan 15, 2015.

Address for reprints: Anthony W. Kim, MD, Section of Thoracic Surgery, Yale School of Medicine, 330 Cedar St, BB 205, New Haven, CT 06520 (E-mail: anthony. kim@yale.edu).

J Thorac Cardiovasc Surg 2015; 149:751

$0022-5223 / \$ 36.00$

Copyright (c) 2015 by The American Association for Thoracic Surgery http://dx.doi.org/10.1016/j.jtcvs.2014.11.065
}

to closure occasionally encountered with the more traditional open thoracostomies. ${ }^{1}$ The reality is that data such as these, outside of a multicenter collaborative effort, may be difficult to achieve. Furthermore, the very nature of this issue does not lend itself well to being answered by other means, such as through a prospective, randomized, controlled trial, for a variety of reasons.

Although the results of Perentes and colleagues' experience are impressive, ${ }^{1}$ they still should be interpreted with some caveats. Some surgeons would argue that Perentes and colleagues' time to closure ${ }^{1}$ was, in fact, not as rapid as achieved by others with more conventional or alternative techniques described previously. ${ }^{2-4}$ This observation raises the probability that other factors, either not measured or not evaluated in their study, could have affected their findings. Additionally, the nature of the dressing changes, particularly the fact that general anesthesia is required repeatedly and the wound vacuum therapy is associated with some inherent expenses, may cut against the grain of cost containment, which is a significant issue in virtually every corner of the earth. Finally, except for an initial culture of the pleural cavity before the initiation of wound vacuum therapy, the benefit of using subsequent cultures to guide therapy remains unresolved. This issue is not made definitively clearer with the data from the series of Perentes and colleagues. ${ }^{1}$

Ultimately though, Perentes and colleagues ${ }^{1}$ should be congratulated for their excellent results, as well as for providing useful and valuable information that the practicing surgeon can readily apply when faced with the challenges associated with the infected postpneumonectomy chest cavity. The success of their wound vacuum therapy speaks to the fact that their approach may allow the surgeon to realize delayed gratification possibly earlier than would be expected with conventional techniques - and in circumstances that otherwise may not be associated with any gratification.

\section{References}

1. Perentes JY, Adbelnour-Berchtold E, Blatter J, Lovis A, Ris HB, Krueger T, et al Vacuum-assisted closure device for the management of infected postpneumonectomy chest cavities. J Thorac Cardiovasc Surg. 2015;149:745-50.

2. Schneiter D, Grodzki T, Lardinois D, Kestenholz PB, Wojcik J, Kubisa B, et al Accelerated treatment of postpneumonectomy empyema: a binational long-term study. J Thorac Cardiovasc Surg. 2008;136:179-85.

3. Pairolero PC, Arnold PG, Trastek VF, Meland NB, Kay PP. Postpneumonectomy empyema. The role of intrathoracic muscle transposition. J Thorac Cardiovasc Surg. 1990;99:958-66; discussion 966-8.

4. Bagan P, Boissier F, Berna P, Badia A, Le Pimpec-Barthes F, Souilamas R, et al Postpneumonectomy empyema treated with a combination of antibiotic irrigation followed by videothoracoscopic debridement. J Thorac Cardiovasc Surg. 2006 132:708-10. 